\title{
PROFESSORES DE FÍSICA DA REDE ESTADUAL DE ENSINO E SUAS PRÁTICAS PEDAGÓGICAS EM FÍSICA MODERNA E CONTEMPORÂNEA
}

\section{PHYSICS TEACHERS AND THEIR PEDAGOGICAL PRACTICES IN MODERN AND CONTEMPORARY PHYSICS}

\author{
Ivanilda Higa ${ }^{1}$ \\ Tony Marcio Groch ${ }^{2}$
}

RESUMO: Uma das preocupações da área de pesquisa ensino de Física é a abordagem da Física Moderna e Contemporânea (FMC) no ensino médio (EM). A necessidade de que tais conteúdos sejam trabalhados nesse período da vida escolar também já é preconizada pelas próprias orientações curriculares, sejam as nacionais ou estaduais. Esperase assim que, para além das pesquisas em ensino, esse movimento esteja também chegando à sala de aula. Apresentamos neste trabalho uma pesquisa realizada com professores de Física do EM na qual buscamos compreender se e como os educadores estão abordando tais conteúdos em suas salas de aula. Os instrumentos de pesquisa empírica utilizados foram: um questionário respondido por 25 professores e entrevistas do tipo semiestruturado com cinco professores selecionados, todos da rede estadual de ensino. Os referenciais que subsidiam o trabalho são os conceitos de cultura escolar de Forquin (1993) e a Teoria da Transposição Didática, de Chevallard (1997). Os resultados indicam que, apesar das dúvidas e dificuldades inerentes a todo processo de inovação educacional, os professores têm abordado esses conteúdos; alguns usam práticas didáticas bastante estruturadas, enquanto outros, inclusive, atingem a terapêutica didática.

Palavras-chave: Cultura escolar. Transposição didática. Ensino de Física Moderna e Contemporânea. Práticas pedagógicas.

\begin{abstract}
One of the concerns of the Physics teaching area is the Modern and Contemporary Physics teaching (MCP) at secondary school (SS). The necessity of this subject matter incorporation at SS is even recommended in the Brazilian curriculum guidelines, both national and state ones. In this way, it is expected that this changes can reach the classroom, at Physics classes. In this paper, it is presented a research carried out with Physics teachers, in which it is aimed to understand if and how these teachers are approaching those contents in their classrooms. Data were built through Questionnaire (answered by 25 teachers) and semi structured interviews (with 5 teachers), all of them working in state schools. The theoretical approach is based on the concepts of School Culture (Forquin, 1993) and Didactic Transposition Theory (Chevallard, 1997). The results indicate that, despite of doubts and difficulties inherent to all educational innovation process, these teachers have taught these contents, and some of them with very well structured pedagogical proposals, reaching the didactic therapeutic.

Keywords: school culture, Didactic Transposition, Modern and Contemporary Physics teaching; pedagogical practices.
\end{abstract}

Doutora. UFPR, Setor de Educação (DTPEN e PPGE). E-mail: ivanilda@ufpr.br

2 Mestre. UFPR, Universidade Positivo e Col. Estadual do Paraná. E-mail: tomagro@yahoo.com.br 


\section{Introdução}

Muitas são as discussões acerca do ensino de Física e, dentre as diversas linhas temáticas, o ensino da Física Moderna e Contemporânea (FMC) no ensino médio (EM) tem sido uma das vertentes defendidas quando se discutem os conteúdos trabalhados nesse nível da vida escolar. Muitas propostas de ensino e pesquisas têm sido desenvolvidas nessa vertente, com importantes contribuições para a área, conforme evidenciam as revisões de literatura de Ostermann e Pereira (2009) e Monteiro e Nardi (2007).

A defesa de abordar a FMC no ensino médio vem acompanhada de uma ampla gama de justificativas, dentre elas o anseio de uma formação voltada para o exercício da cidadania e a influência dos conhecimentos contemporâneos na sociedade (TERRAZZAN, 1992), bem como o caráter instigante que os temas de FMC têm para os alunos e o reconhecimento da Física como empreendimento humano (OSTERMANN e MOREIRA, 2000).

Em uma revisão de literatura, Ostermann e Moreira (2000) analisaram uma vasta quantidade de publicações sobre esse tema, ressaltando, naquela época, a necessidade de um amadurecimento da pesquisa da área, principalmente no tocante à prática em sala de aula. Pereira e Ostermann (2009), por sua vez, analisaram a produção acadêmica nos periódicos de ensino e ressaltaram a necessidade de que as pesquisas se voltassem mais aos processos conduzidos dentro da sala de aula. Também buscando compreender as tendências das pesquisas nesta área, Monteiro e Nardi (2007) realizaram um levantamento bibliográfico nas atas do Encontro de Pesquisa em Educação em Ciências (Enpec), da primeira (1997) à quinta (2005) edição. Dentre as diversas conclusões a que chegam os autores, ressaltamos a necessidade de se investigar "a compreensão dos professores de Física para a inserção de conteúdos da FMC na educação básica" (MONTEIRO e NARDI, 2007; p. 11). Assim sendo, compreender como os professores se relacionam com materiais e suas propostas desenvolvidas apresenta hoje vital importância (BROCKINGTON, 2005; KARAM, et al, 2007).

Dentro dessa linha, D’Agostin (2008) busca compreender as condições enfrentadas pelos professores que tentam ensinar esses conteúdos no EM, enquanto Loch (2010) estuda como e em que momento do EM os professores os estão abordando. Kikuchi et al. (2013) apresentam uma análise de 13 artigos publicados de 2007 a 2012, onde foram evidenciados diferentes objetivos, como: elaboração, aplicação e/ou avaliação de propostas de ensino de tópicos de FMC, análise de posicionamentos de professores a respeito do ensino de FMC no EM, análise dos conteúdos de FMC presentes em livros didáticos etc. Dentre estes, 11 apresentam propostas de ensino de FMC e/ou avaliações de propostas de ensino aplicadas, evidenciando que tal ensino está ocorrendo em salas de aula com diferentes tópicos e abordagens, porém de maneira pontual.

Entendemos que discutir a abordagem da FMC no ensino médio é discutir a atualização curricular em Física, e compartilhamos da ideia de que tal atualização deve vir acompanhada de uma renovação também nas práticas pedagógicas. Defendemos que as práticas pedagógicas em FMC devem fazer parte da cultura escolar de Física e, para que isso ocorra, é necessário que a transposição didática (TD) apresente características importantes como a criatividade, a operacionalidade e a terapêutica didática.

Neste trabalho, apresentamos parte de uma pesquisa de mestrado $(\mathrm{GROCH}, 2011)$ na qual se procurou compreender de que formas os professores abordam a FMC em suas aulas de Física. Buscamos, na Teoria da Transposição Didática de Chevallard (1997) e no conceito de Cultura Escolar de Forquin (1993), os elementos balizadores das reflexões, para compreendermos as possibilidades da incorporação desses conteúdos na cultura do ensino de Física, analisando dificuldades e possibilidades no processo.

\section{Cultura escolar, transposição didática e a FMC no EM}

Nos múltiplos significados que a cultura pode apresentar, o contexto social é predominante 
na atualidade. Neste trabalho, concebemos que a cultura está ligada à educação; para isso, apropriamo-nos das palavras de Forquin, segundo o qual "a educação não é nada fora da cultura e sem ela" (1993, p.14). As três diferentes dimensões que relacionam cultura e escola (cultura na escola, cultura da escola e cultura escolar) devem ser mais bem explicitadas para que se compreenda de que forma serão tomadas como referência nesta pesquisa.

A cultura na escola reflete os elementos culturais de uma determinada sociedade e terá reflexos tanto na cultura da escola como na cultura escolar. Essa dimensão da cultura é trazida não só pelos alunos e professores, mas também pelo entorno desse espaço pedagógico. Não se pode deixar de ter reconhecida a sua existência, uma vez que ela deve ser conhecida e utilizada dentro de tal espaço.

A escola tem características próprias; portanto, a cultura da escola é o conjunto de "características de vida próprias, seus ritmos e ritos, sua linguagem, seu imaginário, seus modos próprios de regulação e de transgressão, seu regime próprio de produção e de gestão de símbolos" (FORQUIN, 1993, p. 167).

As características próprias da escola, como o tempo organizado em hora-aula (em que o professor necessita organizar o ritmo de seu conteúdo), a seriação e a linguagem característica são fatores que organizam como um determinado conteúdo/tema tem que ser trabalhado. Esse é um conceito unificador da cultura e, quando relacionado com a escola, é utilizado por Forquin (1993) como cultura escolar. Nesse sentido, ensinar os conceitos da Física Moderna e Contemporânea, que ainda não possuem uma organização dentro de tal cultura faz com que seja necessário encontrar os meios próprios, organizados dentro do tempo didático e de uma linguagem apropriada.

Outro referencial que nos guia neste trabalho é o da Transposição Didática, ideia elaborada inicialmente pelo sociólogo Michel Verret, na França, em 1975, em que analisa o caminho percorrido pelo conhecimento científico quando selecionado e organizado visando à sua utilização didática. 0 conjunto de transformações pelas quais passam nos materiais didáticos e nas práticas pedagógicas com a finalidade de organizar um conhecimento (objeto do saber) para ser ensinado, está carregado por uma transposição didática, fazendo com que, dessa forma, a cultura escolar se efetive.

Para Chevallard (1997), a TD é composta por três estatutos ou patamares de saber: savoir savant (o saber sábio), savoir a enseigner (saber a ensinar) e savoir enseigné (saber ensinado).

O saber sábio é aquele elaborado pelos intelectuais e cientistas; é um produto da atividade científica, o saber original, que é tomado como referência da disciplina escolar. Ele sofre transformações dentro da comunidade científica até se tornar público em revistas específicas. Quando essa publicação ocorre, o texto está depurado e em linguagem impessoal, não mostrando as características de sua construção. $O$ saber a ensinar configura como se apresentam os conteúdos dos materiais e dos livros didáticos, sendo a parte específica dos professores, estando diretamente relacionada à didática e à prática de condução de sala de aula. Esse é um dos grandes desafios do professor para realizar tal transposição, pois terá que adaptar os conteúdos curriculares de acordo com aspectos da cultura escolar. Finalmente, o saber ensinado é aquele que de alguma forma foi recebido pelo aluno mediante as adaptações e as transposições feitas pelos cientistas e educadores.

Para Chevallard (1997), um saber deve ser consensual, ou seja, a comunidade escolar não pode ter dúvidas sobre o "valor" daquilo que é ensinado. O conteúdo deve ter uma "verdade" contemporânea ou histórica e isso talvez explique por que temas como a Teoria de Cordas aparecem (ou não) nos programas de ensino e nos livros didáticos.

Além de ser consensual, um saber deve ter operacionalidade, pois, se não for "prático" (no sentindo literal da palavra), não se efetivará na escola em razão das condições concretas sob as quais trabalham os professores - condições estas muitas vezes desfavoráveis ao trabalho pedagógico. Um saber é considerado operacional quando é capaz de ser apresentado em exercícios, atividades e tarefas, possibilitando uma avaliação mais objetiva, tendo muito mais chances de ser transposto e, consequentemente, tornando-se parte da cultura escolar. Esse é um desafio no ensino da FMC, uma vez que esta ainda não possui uma operacionalidade estabelecida. 
Outra característica que definirá o sucesso de uma prática pedagógica é a criatividade didática, pois não basta que o professor utilize recursos adaptados de outro nível de ensino ou de outras práticas desenvolvidas. Estratégias e materiais didáticos devem ser condizentes com o conhecimento científico e também com o cotidiano do aluno, do professor e da escola. Tal criatividade didática se caracteriza por atividades e áreas de estudo que são produzidas para o ensino, porém não possui equivalente na ciência de referência, sendo essa uma atribuição que possibilita que a cultura escolar se efetive.

Quando essas características são reconhecidas na prática pedagógica, poderá ocorrer o que é chamado de terapêutica didática, proposta por Chevallard como um "selo de qualidade" do saber a ensinar, ou seja, que essa prática seja inserida de forma efetiva no currículo escolar, não sendo mais uma experiência isolada e sim uma prática recorrente, como se espera que ocorra com os conteúdos de FMC no EM.

\section{Encaminhamentos metodológicos}

Esta pesquisa é condizente com o viés da pesquisa qualitativa em Educação. Em estudos dessa natureza, todos os participantes devem ser reconhecidos como sujeitos que elaboram conhecimentos e práticas adequadas. Eles possuem conhecimento prático e senso crítico e têm representações relativamente elaboradas, orientando suas ações individuais. A vivência com a pesquisa e o conhecimento da realidade que os sujeitos participantes possuem sobre o problema permite ao pesquisador ir além "para descobrir os fenômenos além das suas aparências imediatas" (CHIZZOTTI, 2010, p. 81).

Buscamos, neste trabalho, compreender de que forma os professores de Física realizam a abordagem da FMC em suas aulas; nesse sentido, inicialmente buscou-se identificar professores dentro desse perfil, para então realizar uma maior aproximação às práticas que desenvolvem em sala de aula.

Para aproximação aos possíveis sujeitos de nossa pesquisa, foi utilizado inicialmente um questionário com questões objetivas e de múltipla escolha. Participaram dessa etapa 25 professores de Física em escolas da rede pública estadual, com os quais o contato foi propiciado por meio de um curso de formação ofertado pela Secretaria de Estado da Educação. Dos 25 respondentes, 92\% tinham formação em Física. Quanto à experiência profissional, sete tinham mais de quinze anos de trabalho; sete, entre dez e quinze anos; seis, entre cinco e dez anos; e cinco tinham menos de cinco anos de experiência.

Para melhor conhecer as práticas pedagógicas de FMC por eles desenvolvidas, foi utilizada então uma entrevista do tipo semiestruturado com alguns professores selecionados. Isso permitiu compreender quais materiais foram utilizados, bem como de que forma se procedeu a avaliação da aprendizagem e do processo pedagógico. A entrevista possibilitou identificar nas práticas pedagógicas de cada professor indícios de criatividade, operacionalidade e a terapêutica didática.

\section{As práticas dos professores no ensino de FMC: entre tradições e inovações}

Conforme explicitado anteriormente, buscou-se, num primeiro momento da pesquisa, identificar professores de Física que abordassem a Física Moderna e Contemporânea em suas aulas no ensino médio, selecionando aqueles que apresentassem indícios de uma prática pedagógica mais bem sistematizada e incorporada de uma forma mais consistente em seu planejamento anual, ou seja, professores cujas práticas em FMC demonstrassem uma certa terapêutica didática. Isso nos permitiu traçar um perfil dos docentes e perceber as dificuldades que eles enfrentam na tentativa de incorporar esses conteúdos ao seu plano de ensino.

Do total de 25 professores que responderam ao questionário, 17 declararam que ensinavam FMC no EM. Dentre os conteúdos elencados no estudo de Ostermann e Moreira (2000), os mais 
citados pelos docentes foram: raios X (12 citações), efeito fotoelétrico e big bang (11 citações) e dualidade onda-partícula, fissão e fusão nuclear e radioatividade (dez citações). Outros conteúdos foram citados, porém menos de dez vezes.

Quanto aos recursos didáticos, os mais utilizados eram vídeos, livros didáticos e textos de divulgação científica, com 14, 11 e 10 citações, respectivamente. Outros recursos foram mencionados, porém com cinco ou menos citações.

Feita essa primeira aproximação, partiu-se para a seleção dos professores a serem entrevistados, dentre aqueles que afirmaram que trabalhavam com temas de FMC. Levaram-se em conta os seguintes critérios: deveriam ter-se colocado disponíveis para serem entrevistados, não poderiam trabalhar na mesma escola que o pesquisador e não poderiam ter sido alunos de graduação deste. Aplicados esses requisitos, foram entrevistados três professores e duas professoras cuja formação inicial e o tempo de docência em Física estão explicitados no Quadro 1. Cada professor é identificado por uma letra.

\begin{tabular}{|c|l|c|}
\hline Professor & \multicolumn{1}{|c|}{ Formação inicial } & Tempo de docência em Física \\
\hline PA & Bacharel e licenciado em Física & 10 anos \\
\hline PB & Ciências com complementação em Física & 10 anos \\
\hline PC & Bacharel e licenciado em Física & 6 anos \\
\hline PD & Bacharel em Matemática e licenciada em Física & 25 anos \\
\hline PE & Licenciado em Física & \\
\hline
\end{tabular}

Quadro 1: Perfil dos entrevistados. Fonte: o autor

Os resultados das entrevistas serão apresentados segundo os seguintes eixos:

1) quanto às justificativas e motivações para trabalhar FMC no EM; e

2) quanto à organização do trabalho pedagógico em FMC.

i) encaminhamento metodológico; e

ii) avaliação da aprendizagem do aluno.

\section{1) Quanto às justificativas e motivações para trabalhar FMC no EM}

Diversas são as razões apresentadas pelos professores para trabalhar FMC no EM: aspecto motivador, influência de cursos institucionais e vestibular e compreensão do cotidiano, apresentadas na sequência.

A motivação é pessoal e intrínseca ao ensino-aprendizagem; os fatores que a causam são diversos. Ela pode partir tanto do aluno como do professor. Seja de onde vier, pode ser um fator incentivador para o trabalho com novos conteúdos que ainda não possuam uma tradição dentro da cultura escolar. Os professores o fazem porque gostam e porque pode ser motivador para os alunos. É o caso de PC, por exemplo:

Em primeiro lugar porque eu gosto... em segundo lugar porque eles gostam... eles gostam de ouvir e perguntam bastante... questionam bastante... principalmente sobre partículas elementares... de que forma toda matéria... fala de quarks... confinados de prótons... coisas que raramente eles escutam... buraco negro... é... o início do universo... esse é o mais polêmico de todos né... big bang...

Por sua vez, PD destaca que, além de seu próprio interesse em ensinar FMC, quer mostrar aos alunos que a Física não é somente aquela que já está estabelecida na cultura escolar: 
locar isso aqui... digamos, é um caminho pra abrir e pra mostrar que a Física não é aquela coisa... só isso e acabou...

PE afirma que a motivação é definida pela própria demanda de parte dos alunos:

[...] geralmente vai ser mais de acordo com a própria turma... está entendendo, quando eu vejo que a turma... eles se desprendem... e querem adquirir mais... querem se aprofundar mais, aí a gente pode de vez em quando entrar com uns tópicos... mas não é sempre que a gente consegue...

Observamos, pelos extratos das entrevistas desses professores, que a motivação ocorre tanto por parte deles quanto dos alunos.

Outro elemento que influencia os professores na inserção da FMC em suas aulas são os cursos institucionais e as Diretrizes Curriculares Estaduais de Física (PARANÁ, 2008), que suscitam o trabalho com FMC ao longo de todo o ensino médio. PB comenta que esse é um dos fatores que o motivaram a trabalhar com o tema:

Olha... eu não sei se foi intuitivo... na verdade a gente acaba indo pra cursos... a gente vê coisas e a gente ouve coisas... quer buscar coisas novas... a gente vê as tendências... e vê também [...] a gente está com novas maneiras de avaliação... os conteúdos... a nossa Diretriz... ele pediu isso... a gente vem acompanhando isso... acho que foi num contexto todo... foi isso...

O vestibular também é um elemento importante, como demonstra $\mathrm{PB}$, que não se esquiva de afirmar que essa medida tem como motivação principal a cobrança do tema no processo seletivo.

o vestibular pede também isso (PB).

Finalmente, a necessidade de compreensão e a utilização dos equipamentos presentes no cotidiano do aluno são citadas, como ressalta PA:

O que me motivou é eu como aluno, que eu sempre falo assim... a Física que eu tive em sala de aula, que às vezes eu sou obrigado a dar porque faz parte do currículo e tal, dependendo, é chato de trabalhar em sala de aula [...] que todo professor de Física, falava, falava e acho que sempre vai falar é que a Física ela está sempre presente no nosso dia-a-dia, e o aluno tem dificuldade de ver onde ela está presente né, ele sabe que a Física, está presente lá no computador, tá mas e daí aonde? Então é esse tipo de coisa que me motivou a correr atrás, o aluno saber explicar coisas que realmente, que ele faz uso no dia a dia que às vezes passa batido (PA).

Apesar de não estar explícito na entrevista, PD afirma (em conversa não gravada) que a Física necessita de se aproximar do aluno, ou seja, este deve ficar mais próximo da tecnologia que faz parte do seu cotidiano.

As justificativas para a inserção da FMC no EM pelo ponto de vista dos pesquisadores da área são várias, como já citadas no início deste trabalho. As razões elencadas pelos professores entrevistados deixam clara a busca por uma atualização curricular, sendo que uns fazem afirmações mais veementemente e outros de forma velada. Da mesma forma que os pesquisadores da área, os professores entrevistados também indicam que essa atualização é um fator motivador para os alunos e para eles próprios, pois os aproxima do cotidiano no qual estão inseridos. As orientações curriculares estaduais também têm influenciado os docentes na inserção da FMC no EM e, da mesma forma que na Física Clássica (FC), os professores citam ainda a necessidade de preparação para o 
vestibular, já que nos últimos anos uma das principais universidades do estado no qual a pesquisa foi desenvolvida começou a incluir, no seu processo de seleção, questões envolvendo principalmente a dualidade onda-partícula e o efeito fotoelétrico.

\section{2) Quanto à organização do trabalho pedagógico em FMC}

\section{i. encaminhamento metodológico}

A estruturação do processo que é conduzido em sala de aula é de vital importância, pois nos permite compreender a operacionalidade didática. As práticas descritas pelos professores entrevistados mostraram alguma forma de operacionalidade, e [...] somente assim poderemos adquirir uma melhor compreensão dos mecanismos utilizados por professores e alunos na construção de conhecimentos relativos a temas de FMC (OSTERMANN e MOREIRA, 2000, p. 414).

O encaminhamento metodológico, juntamente com os materiais e a vertente utilizados, podem fornecer elementos que nos permitirão inferir sobre a criatividade didática e a operacionalidade, sendo eles fundamentais para a efetiva terapêutica didática dos temas de FMC.

Nesta análise, o caminho metodológico é compreendido em três vertentes: a da exploração dos limites dos modelos clássicos; a da não utilização de referências a tais modelos clássicos; e a da escolha de tópicos essenciais (TERRAZZAN, 1994; OSTERMANN e MOREIRA, 2000).

Já no início da entrevista, solicitou-se que os professores destacassem duas das suas práticas em FMC que considerassem mais significativas, pois acreditamos que elas teriam maior possibilidade de passar a compor o seu "acervo pedagógico", ou seja, poderiam estar caminhando para uma terapêutica didática.

O Quadro 2 mostra um resumo dos temas citados pelos professores e quais recursos foram utilizados:

\begin{tabular}{|c|l|l|}
\hline Professor & \multicolumn{1}{|c|}{ Temas destacados } & \multicolumn{1}{|c|}{ Recursos utilizados } \\
\hline PA & $\begin{array}{l}\text { Fissão nuclear } \\
\text { Efeito fotoelétrico e raios X }\end{array}$ & $\begin{array}{l}\text { Simulador, kit de robótica e filtros, câmera } \\
\text { de vídeo, calculadora solar e internet }\end{array}$ \\
\hline PB & Origem do universo (Big Bang) e fusão nuclear & Internet \\
\hline PC & Origem do universo e Física Quântica & Fotos e internet \\
\hline PD & $\begin{array}{l}\text { Dualidade onda-partícula } \\
\text { Fibra óptica }\end{array}$ & $\begin{array}{l}\text { Internet } \\
\text { Vídeo e fibra óptica }\end{array}$ \\
\hline PE & Relatividade especial e estrutura molecular & Não foi possível identificar \\
\hline
\end{tabular}

Quadro 2: Temas e materiais utilizados nas práticas docentes. Fonte: o autor

Para este item, optou-se por apresentar os resultados da entrevista com cada professor separadamente, para não se perder de vista a totalidade de suas práticas e os seus caminhos no ensino da FMC.

\section{Professor A (PA)}

PA escolhe como mais relevantes suas práticas de fusão e fissão nuclear e efeito fotoelétrico. Na primeira, ele busca uma interação com a Física Clássica, não procurando os seus limites, mas sim uma sequência que considera lógica.

Eu tinha começado conteúdo de calorimetria, a parte de calor tal, e daí dentro dessa parte de calorimetria já dei um gancho no... voltei um pouquinho na parte de dilatação e usei um pouquinho a dilatação dos gases, e daí, como sempre 
em todo ano acontece, algum aluno pergunta sobre explosão... o que é explosão... tal... e daí nessa definição numa aula eu consegui explicar o que é uma explosão né, e daí na aula seguinte eu trouxe essa historinha aqui... que aquela turma fazia parte de um país e que nosso país estava em guerra, e foi como se tivesse... fiz associação com a história do mundo e tal, e essa foi a motivação pra começar... então o gancho foi a pergunta que todo ano aparece...é a questão das explosões né [...]

A discussão de um importante marco histórico - a Segunda Guerra Mundial - e o símbolo do seu término (o lançamento da bomba nuclear pelos Estados Unidos sobre o Japão) são utilizados por PA na segunda série, na qual busca uma interdisciplinaridade com a Química:

[...] daí na parte de fissão e fusão nuclear na segunda série... não foi experimento... eu trouxe só imagens né... a respeito das bombas atômicas de Hiroshima e Nagasaki daí eu falei de todo o processo... do projeto Manhattan e tal... daí eles se assustam que é um negócio relativamente simples de entender ali... e é tão perigoso assim... foi aí que eu trabalhei a fissão e fusão nuclear... daí a gente comenta um pouquinho da radioatividade... aproveita que o professor de Química "tava" dando decaimento... e tal... daí eu juntei... não foi muito experimento, mas... teórico demonstrativo [...]

Outra estratégia utilizada por PA nessa atividade foi o que ele chama de "pesquisa":

Na aula de fusão e fissão eu usei pesquisa deles mesmo... não deu pra fazer aqui na escola, queria ter levado eles ao laboratório e mostrar como se faz uma pesquisa... que no ensino médio apesar de terem estudado um monte, ainda não sabem fazer... Mas eles trouxeram texto para sala de aula e a gente fez um debate

A pesquisa na internet é utilizada pelo professor como forma de condução do seu encaminhamento pedagógico no ensino de fissão e fusão nuclear. Ele propõe aos alunos a organização de quatro grupos. Um grupo seria a favor da construção de uma bomba nuclear; outro seria contra; o terceiro (chamado de "jornalistas") teria o papel de questionador das defesas dos dois primeiros grupos; e o quarto grupo seria responsável pela tomada da decisão acerca da construção de tal bomba. Percebe-se que essa prática pedagógica é inspirada no trabalho de Samagaia e Peduzzi (2004). Inclusive, tal inspiração é declarada por ele em outros momentos da entrevista.

O debate foi adotado como estratégia e a preparação em grupos foi feita durante as próprias aulas, nas quais o professor utilizava a orientação de rumos, chamada por ele de "intervenção" aos materiais que os alunos traziam:

[...] antes de fazer o debate eu liberei algumas aulas para eles se separarem em grupos, então um grupo era a favor, um grupo era contra, um grupo era de jornalistas que deviam saber um pouquinho de cada coisa... então nestas aulas eu ia intervindo eu via os materiais que eles iam trazendo, eu dizia veja esse e esse ponto e tal para que na hora do debate para defender uma ideia.

Os grupos teriam um tempo estipulado para a apresentação de seus argumentos e, de início, cada um deveria apresentar uma defesa de aproximadamente vinte minutos. O professor deu liberdade, e os alunos apresentaram a sua criatividade, como o caso da produção de um telejornal:

[...] na verdade uma comissão que iria decidir se íamos construir a bomba nuclear ou não, foi como um jogo em sala de aula. Então, em uma aula cada grupo apresentou a sua opinião o grupo a favor e o grupo contra, teve uma das turmas 
que um grupo fez um telejornal, como se tivesse assistindo, o moço que apresentou, fazendo entrevista como os participantes dos grupos.

Após a defesa inicial, seria o momento dos questionamentos mútuos, em que o docente destacou a ótima participação dos alunos:

Depois de apresentadas as ideias, nesta aula era somente para apresentar as ideias, vinte minutos para cada grupo, e na aula seguinte o debate, onde um grupo poderia fazer pergunta ao outro grupo, onde até a coordenadora da escola, desculpe, supervisora, a escola adorou a ideia, o rendimento dos alunos depois do conteúdo foi fantástico, em sala de aula também tem aqueles alunos que não querem participar mesmo, mas a maioria assim, preferiu esse tipo de aula do que a tradicional, do quadro negro.

PA utiliza uma estratégia que não é muito frequente na cultura escolar de ensino de Física: o debate. A sua conclusão foi que houve um aproveitamento "fantástico". Deve-se ressaltar que o professor precisou desenvolver uma operacionalidade em relação ao tempo e espaço didáticos que permitisse a realização dessa estratégia. Durante a apresentação das equipes, houve também criatividade didática por parte dos alunos, com o telejornal. PA destaca que a maioria dos estudantes preferiu as aulas com esse tipo de dinamismo; entretanto, destaca que alguns não queriam participar. Isso evidencia que a superação das tradicionais estratégias de ensino de Física em favor de práticas inovadoras também pode ser um obstáculo entre os próprios estudantes, acostumados às formas convencionais presentes na cultura escolar do ensino dessa disciplina, com explicações do professor e resolução de exercícios pelos alunos.

Esse professor relata ainda o uso de recursos em vídeo:

Teve um aluno que trouxe um documentário do.. acho que era da BBC que falava sobre a bomba de Hiroshima e Nagasaki, nesse documentário ele explicava um pouquinho das reações ali e mostrava imagens da bomba e tal, e eu trouxe na Internet achei um videozinho da bomba atômica, de um teste acho que no Novo México, você acha fácil na Internet [...]

Para o ensino do efeito fotoelétrico, PA também demonstra a necessidade de relacioná-lo a conteúdos de Física clássica (FC), conforme o extrato abaixo evidencia:

[...] é a eletricidade eu começo com a eletrodinâmica né, daí explico o que é corrente elétrica... tal... explico o que é diferença de potencial, explico que a gente precisa de uma fonte de energia... daí eu trago, na verdade eu não trago, porque eu não tenho, mas algum aluno sempre acaba tendo uma calculadora que não tem bateria, mas que tem aquela plaquinha, aí vem aquela pergunta, se não tem bateria como funciona? Daí então que vem o gancho pra começar com o efeito fotoelétrico... começo com o movimento ondulatório, o que é uma onda, o que é... aí volto na lousa... como a onda [...]

O professor utiliza o que podemos chamar de "material de baixo custo" ou "alternativo", como o sensor de uma calculadora, sem prescindir dae formalização matemática. Outra alternativa apontada no encaminhamento metodológico é trabalhar os temas de maneira conceitual, conforme afirma PA quando trata da quantização:

Foi mais conceitual, até mostrei a relação da energia da onda com a energia do elétron que sai dali tal, mostrei que não é qualquer átomo que você consegue fazer isso né, mas não pedi nenhuma conta pra eles, eu só demonstrei as contas. 
PA mostra uma grande preocupação do trabalho com o material concreto, relatando uma prática utilizando materiais tradicionais de laboratório didático de Física, mas também com equipamentos do cotidiano dos alunos, no caso, a "calculadora solar":

[...] o efeito fotoelétrico a calculadorinha né... mostrei pra eles e consegui medir o potencial que sai daquela plaquinha da calculadora eles acharam bem legal... daí eu mostrei a pilha... para eles entenderem o funcionamento do multímetro... medi lá tranquilo... daí medi o efeito fotoelétrico daí eles entenderam que sai energia daquela plaquinha lá... é o que faz funcionar... daí a atenção deles no dia da aula e na aula seguinte... é fantástico eles gostam muito quando você traz coisas diferentes.

Por meio da preocupação, dos gestos e do tom de voz em alguns momentos da entrevista, percebe-se que os encaminhamentos e estratégias didáticas não habituais nas aulas de Física trazem ao próprio professor a necessidade de justificar que, apesar de não estar usando a cultura estabelecida no ensino dessa disciplina, os seus encaminhamentos se sustentam:

[...] daí na parte de fissão e fusão nuclear na segunda série... não foi experimento... eu trouxe só imagens né [...] radioatividade daí a gente aproveita que o professor de Química estava dando decaimento... e tal... daí eu juntei... não foi muito experimento mas... teórico demonstrativo [...] (PA).

O professor relata também outra prática, em que discute o tema raio $\mathrm{X}$ conceitualmente:

[...] do raio $X$ eu não cheguei a fazer experiências com eles né... mas eu mostrei, falei pra eles de que quando você freia um elétron, produz raio $X$ e tal e falei da televisão. Daí eles se assustam... quando a televisão que apesar que todos estão ali... mas que... não é perigoso para eles... [...] tem raio $X$, tem radiação [...]

Ao ressaltar que não fez experiências em laboratório, PA parece preocupado com a ausência desse tipo de atividade, recorrentemente defendida para o ensino de Física, o que indica que, embora esses conteúdos sejam "inovadores", a preocupação com a cultura estabelecida do ensino dessa disciplina é premente.

Quanto às dificuldades para trabalhar com temas de FMC, PA destaca que a tradição cultural do currículo de Física foi um grande entrave e que necessitou aguardar um momento propício para desenvolver as práticas pedagógicas almejadas. A relação entre a extensão dos conteúdos e o tempo didático disponível também foi um elemento dificultador:

Em sala de aula eu comecei... a ideia eu já tinha ha bastante tempo atrás...mas como era novo aqui no colégio e tal... eu dependia de outros professores acabava não colocando "isso" no planejamento, daí os professores mais antigos foram saindo aqui do colégio, ai eu comecei a mudar um pouquinho [...] então este ano eu só consegui colocar um pouquinho de coisa porque o currículo que é gigantesco e o tempo é curto... no ensino por bloco à noite eu coloquei [...] o efeito fotoelétrico... na faculdade eu tive as matérias normais do bacharelado, né... então em sala de aula esse ano consegui colocar direitinho o efeito fotoelétrico.

Finalmente, podemos destacar como esse professor analisa o sucesso de seu trabalho, quais encaminhamentos trouxeram resultados considerados positivos e quais necessitam de ajustes ou novas estratégias. Essa avaliação pelo próprio docente é de suma importância: a prática desenvolvida deve ser operacional, visto que isso define se o educador em questão irá ou não trabalhar essa experiência didática novamente. PA comenta sobre seu trabalho: 
Olha eu gostei bastante disso aí, então eu quero ver se para o próximo ano, principalmente com 3ㅇan ano, eu pego temas mais atuais para eles, que nem eu 'tava' com a revista Galileu aqui, uma coisa muito simples ali que é o grafeno... não sei se você já viu? [...] Aí eu quero ver se para o ano que vem eu pego as turmas de terceiro ano e faço a aula desse gênero, pego atualidades, coisa que está presente no dia a dia pra gente ver a Física que tá aplicada ali, daí provavelmente a gente volte com o efeito fotoelétrico e provavelmente a gente vá além disso [...]

No extrato acima, observa-se que ele ficou satisfeito com o encaminhamento proposto. Disso resulta sua vontade de "aplicá-lo" novamente e ampliar os temas tratados com seus alunos. Os encaminhamentos metodológicos por ele utilizados nos mostram indícios significativos de criatividade didática, por exemplo, quando ele utiliza uma calculadora solar, material que não foi desenvolvido para esse fim. Também são ressaltados o "jogo" e o debate, estratégias incomuns na cultura escolar do ensino de Física. Consideramos que suas práticas possuem indícios mais fortes da criatividade e operacionalidade didática. Assim, compreendemos que o caminho que está sendo trilhado por ele parece estar encaminhando tais práticas para uma terapêutica didática.

\section{Professora B (PB)}

Essa professora cita que aborda os temas origem do universo e fusão e fissão nuclear:

A origem do universo... a origem do universo... como que começou... mas pelo lado físico né... toda aquela, aquelas experiências em si que foram feitas... eu colocando as possíveis né, o que poderia ser feito no universo exatamente... como seria ali... e a história do big bang, foi acho a que [...] da história do big bang foi um espetáculo... aí eles: "aí era isso"... o que estava lá a parte deles era teoria... só a teoria... mais nada.

E também vamos citar aqui a fusão nuclear, que eles colocaram também como experiências... mostrando assim slides né... como que seria... eles juntaram e fizeram um programa dentro do computador mostrando tal... muito legal... foi uma experiência única $[. .$.

Ela afirma que o enfoque dado ao tema depende da série e do momento do ano, superando assim a crítica de que esses conteúdos não devem figurar apenas no final do 3 o ano do ensino médio:

[...] daí também depende do ano que você trabalha e... normalmente você trabalha no terceiro ano do Dr. Quantum... é no terceiro ano [...] A fibra ótica a gente trabalha quando vai trabalhar... é segundo ano.

Sobre a origem do universo, os materiais utilizados foram preparados pelos próprios alunos, organizando uma dramatização:

Na verdade foi assim, eles buscavam... até o 3ㅇ ano [...] montaram, as experiências assim né... colocando... digamos assim, simulando planetas e fazendo estourando... o planeta estourando no outro e formando outra... sabe... uma outra... uma cratera... ficou muito legal sabe... bem bacana.

No caso da fusão nuclear, os alunos fizeram uma apresentação, atividade para a qual eles mesmos buscaram imagens:

Na verdade foi a Internet! [...] é que eu tinha um aluno na sala que ele auxiliou em tudo... foi meu monitor em todas... ele tinha um acesso perfeito sabe... a parte né... mídias, tudo assim... [...] e eles montaram a experiência em cima de 
digamos assim... de... na parte de computadores assim... [...] mas antes eles colocam imagens, em cima de imagens... em cima de cores... sabe... foi feito dessa forma... uma coisa bem diferente [...]

Também foi utilizado o laboratório de informática com acesso à internet, com a monitoria de um aluno que possuía maior conhecimento em "navegação" e montagem de apresentação:

[...] esses sites pra eles pesquisarem... fornecia assim materiais... foi o que eu forneci... então eu montei o kit pra eles... e entreguei... tá façam [...]

Essa prática fez parte de uma feira de ciências:

[...] eles apresentaram uma feira de ciências, que foram cinco dias, foi a feira assim... a semana toda... foi num momento de exposições.

PB mostra indícios de criatividade didática e operacionalidade. Pela sua entrevista, percebeuse que, embora ainda não possua uma terapêutica no ensino de conteúdos de FMC, ela está construindo um caminho nesse sentido.

\section{Professor C (PC)}

Esse professor destaca em sua entrevista os temas de cosmologia e física quântica e descreve como executa a sua prática docente:

A parte mais introdutória, que você vai potências de dez e notação científica eu sempre pincelo um pouco sobre isso... pra falar de ordens de grandeza... pra eles já aprenderem a trabalhar com base dez, e ver ali o limite de quando começa o mundo quântico, ou quando começa o macrocosmo né... nesse sentido [...]

O viés apresentado foi de experiências ainda incipientes quanto a temas de FMC, apresentando apenas fragmentos de tópicos:

[...] A quântica é mais na parte introdutória pra primeiro ano... porque eu comento, porque isso desperta mesmo... bastante interesse da parte deles [...]

PC também afirma que o enfoque dado ao tema depende da série e do momento do ano e, da mesma maneira que $\mathrm{PB}$, que a FMC não figura no final do 3 o ano:

Aí dependendo da época eu... esse ano eu vou dar no terceiro ano gravitação... Lá no finalzinho... normalmente eu tava dando no comecinho do segundo ano... por causa do livro deles... mais aí agora eu resolvi jogar lá pro final do terceiro ano... vamos ver o que que dá... aí fica mais "relax" pra eles... fim de ano [...]

A internet oferece recursos bastante vastos em vários segmentos, como no caso das imagens do telescópio Hubble, que foram utilizadas por PC no ensino de cosmologia:

O único recurso que eu uso é em geral, fotos de satélite... galáxias, aglomerados de galáxias, quando eu vou falar de cosmologia, né... na parte de ísica quântica, não tenho nada assim preparado... no máximo fotos... do Hubble principalmente dos Estados Unidos... mais bonitinho... tal... os recursos da TV [...]

Também observamos em PC indícios de criatividade e operacionalidade, dois critérios sem os 
quais a terapêutica fica comprometida. Pelo que se observa em seus extratos, as suas práticas ainda parecem superficiais, ficando mais como informação do que como novo conhecimento em FMC. Ainda que pareçam superficiais, são práticas importantes, que evidenciam um professor que está buscando caminhos e formas de abordagens desses conteúdos.

\section{Professora D (PD)}

Os temas destacados por PD na entrevista foram a dualidade onda-partícula e a fibra óptica. $\mathrm{Na}$ abordagem da dualidade onda-partícula, ela relata a utilização de vídeo:

A dualidade onda-partícula. Eu utilizei um vídeo... da USP... um vídeo bastante conhecido... acho que Dr. Quantum. Esse vídeo é bem interessante, eles ficam muito apegados no vídeo [...]

Os vídeos são um rico acervo e as ferramentas necessárias para sua obtenção na internet bem acessíveis. Com conhecimento básico de informática, o professor poderá fazer o seu uso com excelente qualidade. Assuntos que muitos docentes definem como difícil de descrever e explicar, como no caso da dualidade onda-partícula, podem ser beneficiados com esse recurso. Foi isso o que fez PD, em uma animação que trata os conceitos com relativa propriedade.

Do vídeo do Dr. Quantum... eles ficam muito impressionados... eles acham que não é... que não acontece... mas como isso... se o elétron pensa... mas não... o elétron não pensa... o elétron tem comportamento alterado diante do medidor... ele tem um comportamento alterado... o medidor altera o comportamento dele... mas ele é inteligente? Não, ele não é inteligente... ele simplesmente tem um comportamento alterado diante daquele medidor [...]

Sobre a utilização desse vídeo, a professora destaca que há a necessidade de retomada, ou seja, a exibição linear do vídeo não é suficiente. Ademais, o papel do professor na condução dos questionamentos é fundamental:

Você passa uma vez... depois você retoma... volta passa um pedacinho... para [...] Eles fazem... eles querem fazer retomada... eles pedem... ah professora, deixa eu ver de novo... não entendi aquela parte... normalmente quando você termina o vídeo e você questiona... mas eu não entendi [...]

Além do vídeo, PD ainda utiliza uma atividade prática, conforme explica:

[...] utilizei uma cuba de vidro que eu mandei confeccionar... poderia ter sido uma cuba de vidro maior... que tivesse um refratário talvez... coloquei em cima de um retroprojetor... e fixei duas réguas... e deixei uma fenda... como na experiência que a gente vê no desenho... dos livros... daí você coloca uma lâmina d'água... e com a régua mesmo... você coloca a régua na lâmina d'água e retira... você vai provocar ondas paralelas que a hora que ela passa pela fenda... elas vão paralelas e entram anguladas... então isso aí eles veem no projetor... você projeta isso na parede... o que você está mostrando na cuba... que está em cima do teu projetor... como se fosse... um... como é que se diz... um slide... ele vai pra parede e eles veem a onda caminhando na parede... eles gostam muito de ver isso $[\ldots]$

Paratrabalharotemafibraóptica, PDutilizaumadereçobemcomumemlojas dotipo “1,99", mostrandouma preocupação principalmenteem relaçãoao modocomoaluzsepropagadentrodeumafibra: 
A fibra óptica a gente trabalha quando vai trabalhar... é segundo ano... com o assunto de luz né... e a gente mostra pra eles o... hoje a gente tem na casa de festa... aquele... é o... eu não sei o nome [...] uma luminária... que tem aqueles cabelinhos... fiozinhos que parecem quase anzóis... sabe, soltos... aí você mostra a "luzinha" que se transporta no fiozinho... aí você mostra pra eles... e a reflexão total que eu coloco numa cuba de vidro... uma experiência bem simples... e um raio laser... aí você projeta o raio laser numa água... numa cuba... aí você procura o ângulo de reflexão total... e aí eles veem o raio laser bate na água e volta... e fica aprisionado dentro do vidro... eles gostam muito de ver essa experiência [...]

Pelo que se percebe nos extratos, ela utiliza atividades que buscam os limites da teoria clássica. Entretanto, a entrevista foi limitadora na compreensão dessa prática especificamente, não conseguindo esclarecer como ela foi desenvolvida. Haveria a necessidade de um acompanhamento mais detalhado para conseguirmos identificar os indícios de criatividade didática e operacionalidade.

Fibra óptica... na verdade são várias aulas pra você chegar a falar da fibra ótica né... você tem que desenvolver todo conceito de luz... depois de reflexão da luz... depois de ângulo limite... e aí você vai entrar na fibra ótica... agora a experiência em si... é simples... em menos de meia aula... você faz a experiência... e aí eles fazem um relatório... terminam em casa... e te entregam.

PD aponta que o laboratório didático de Física é de fundamental importância nas aulas da disciplina, permitindo:

[...] chegar mais informações... ter mais acesso até mesmo no próprio colégio, aí esse tipo de informação... mas como também algumas matérias que pudessem também... até trabalhar em sala de aula... que nem laboratório, disponível não tem... o colégio que tem laboratório geralmente é depósito... aí no laboratório de empilha livro... um monte de coisa menos o espaço preparado pra você trabalhar com o aluno, laboratório principalmente é o que falei... o que eu mais trabalho como aula prática, seria isso, vou, pesquiso alguma coisa, fuço por ali, e faço eles conseguirem material... a gente corre atrás, consegue material... monta ali em sala de aula, e realiza experiência em sala de aula [...]

PD aponta uma realidade de não valorização das atividades de laboratório na escola. Esses espaços se tornam depósitos ou são subutilizados, por falta de carga horária específica para o preparo das práticas, ou mesmo pela falta de um professor responsável por esse espaço pedagógico.

\section{Professor E (PE)}

PE destaca como relevantes em seu trabalho a relatividade e a estrutura molecular:

Relatividade... é que eu não trabalho coisas isoladas, eu procuro trabalhar dentro dos contextos gerais né, o que eu informo no sentido de relatividade é sempre abordando o que, que as coisas não são fechadas e sim abertas... o que eu vou falando "gente tudo é relativo" o que a relatividade mostra pra gente é isso daí... que não existe nada fechado e nada fixo... em todas as áreas sejam elas... tanto na ótica ou até mesmo na eletricidade... não é só na mecânica que a relatividade pode ser trabalhada... eles têm essa ideia... relatividade o que tá mostrando ali que as coisas dependem do ponto de vista que se observa, e de quem está observando... então eu sempre procuro abordar isso com eles em todas as séries... a relatividade, quando a gente fala relatividade... que é mostra isso pra você... o quanto você está focando e "daonde" você está focando, mui- 
tas vezes depende de como você olha e de como você olha, você vai ter um foco diferente da coisa [...]

Durante a entrevista não foi possível identificar os elementos de criatividade e operacionalidade didática, também não ficando claro como essas práticas ocorreram.

\begin{abstract}
A gente pega mais no terceiro ano, quando vai fazer a introdução a respeito da própria... do eletromagnetismo, a gente fundamenta tudo em cima de que... que eu falo pra eles ó, isso vai tá fundamentado onde... justamente... principalmente por causa do átomo de Bohr... onde desenvolve o átomo de Bohr... quase toda essa dinâmica nova a respeito da estrutura do material... aí sim você começa a ter clareza... então sempre nos terceiros anos no início eu falo sobre o átomo de Bohr... apesar de que isso já é quinta... mas eu volto com eles o modelo atômico... todo aquele sistema né.... os elétrons... o núcleo... pra eles terem uma ideia de eletricidade ... aí eu falo pra eles... nós vamos usar o que... aplicado ao elétron... tá mas "daonde" vem essa base? Aí eu mostro pra ele [...]
\end{abstract}

Uma das maiores reclamações dos professores é a escassez de material didático em FMC, o que pesquisadores como Rezende Jr. (2001) também apontam como um dos gargalos para a efetiva implantação desses temas no currículo de Física. Essa também é uma preocupação apresentada por PE:

\begin{abstract}
Apenas a explicação... entende... não tem muito material palpável... pra se trabalhar né [...] É mais também comentando, porque a gente não tem material... pra mostrar pra eles... pra fazer assim uma experiência bem mais clara... a gente comenta a respeito da fibra óptica... que ela é atual... que ela está sendo utilizada, hoje... ela tem desenvolvido muito... até o próprio sistema de telecomunicações é tudo em cima de fibra óptica... então eu dou uma contada pra eles... dou uma ideia pra eles... só pra eles não ficarem tão alheios ao assunto [...]
\end{abstract}

Todos os professores entrevistados evidenciaram a necessidade de trabalhar os temas de FMC "pulverizados" ao longo todo o ensino médio pois, conforme Karam et al. (2007, p. 113) têm defendido,

[...] a mesma não deve ser feita apenas no final do terceiro ano, após o eletromagnetismo, mas sim organicamente incorporada à apresentação e ao desenvolvimento das teorias clássicas.

Em relação às três vertentes para o encaminhamento metodológico, verificamos que quase todos os professores utilizam a abordagem de tópicos essenciais, mas alguns, apesar de se enquadrarem nessa vertente, buscam nesse momento explorar também o limite da teoria clássica, como é o caso de PA.

Os professores apresentam em seus extratos a dificuldade da inserção dos conteúdos de FMC; entretanto, buscam colocar em ação uma criatividade didática e uma correspondente operacionalidade dos assuntos tratados, pois percebe-se que abordam a FMC de maneira diferente do que usualmente abordam a FC.

\title{
ii. avaliação
}

Para a compreensão dos processos avaliativos, buscamos analisar os instrumentos utilizados pelos professores e a forma como eles são empregados.

Uma das estratégias de avaliação utilizadas foi a de relatório, proposta por PB. 
Foi feito o relatório de experiência [...] A gente... eu senti bastante interessados... peço pra eles fazerem um relatório do material utilizado... o que foi que o professor explorou ... qual foi o assunto explorado... o conteúdo mencionado... o que foi que eles entenderam do conteúdo que foi explorado... com as palavras deles... pra eles escreverem... eu faço como se fosse uma provinha... uma avaliação valendo um ponto... e infelizmente pra eles tudo tem que valer muito ponto [...]

Outra forma de avaliação proposta por PA foi qualificar subjetivamente a participação dos alunos no debate, como ele mesmo afirma:

Pela participação [...] Tinha assim, aquele que só ficou ouvindo assim, ele participou do debate, prestou atenção... só aquele que não quis prestar atenção mesmo, que ficava conversando assim, depois eu tiver que passar um trabalho escrito pra ele, mas o restante só na participação mesmo, teve aqueles que queriam... espera um pouquinho, deixa o outro perguntar... ele queria tá sempre ou perguntando ou respondendo.

PA avalia tanto os conteúdos conceituais como os atitudinais. A dúvida de como avaliar um conteúdo que ainda é incipiente na cultura escolar de Física torna-se um problema a ser superado, conforme também demonstram os extratos da fala de PC:

Mas aí eu vejo que é um problema muito grande de fazer uma avaliação de alguma coisa assim... isso eu não sei como proceder né... se você dá um conteúdo assim... avalia o aluno eu acho complicado [...] Não sei como encaixar isso no protocolo de avaliação... isso eu nunca cobro... nunca cobro nada de Física moderna em termos de avaliação [...]

É... eu gostaria... pelo menos uma "praticazinha" pra eles fazerem um relatório... coisa assim, que daí já entra uma avaliaçãozinha... que daí já formaliza um pouco... formaliza mais [...]

Enquadrar Física moderna em algum tipo de padrão de avaliação... porque não dá pra entrar muito na Matemática né... raras coisas da Física Moderna que têm uma coisa mais simples né... e isso já é um problema né... então seria uma coisa muito mais conceitual a princípio... por isso que eu tenho vontade de achar algum tipo de experiência simples né... de se fazer... porque aí pelo menos teria algo prático revelando o mundo quântico por exemplo... isso seria bacana [...]

Uma das principais dificuldades do ensino é a avaliação. Quando o grupo de estudantes é composto então pelo aluno trabalhador e do Ensino de Jovens e Adultos (EJA), como é o caso do contexto escolar da PD, existem ainda outros elementos dificultadores:

É... como era ensino como noturno... não era [...] regular né... nós tínhamos tempo, tinha bastante tempo... a carga horária tudo ali... como momento avaliativo... certo assim... mas avaliativo, não foi avaliativo de grupo... foi desempenho individual... foi desempenho individual [...] Teve, teve até uma parte escrita [...] Os alunos tinham que montar um relatório [...] porque daí toda experiência... tem que ter um relatório [...]

Nesse caso, PD também solicitou a confecção de um relatório, pois este tipo de trabalho escrito é necessário em sua concepção de "atividades práticas". Talvez ela esteja usando a transposição de uma prática recorrente no ensino superior (nas disciplinas "experimentais"), de forma linear ao outro nível de ensino, não conseguindo propor outras formas de produção pelo estudante. 


\section{Considerações finais}

Neste trabalho analisamos como as práticas docentes no ensino de Física Moderna e Contemporânea estão sendo desenvolvidas por cinco professores de Física de escolas públicas estaduais do EM. Procuramos compreender quais conteúdos são ensinados e como eles estão sendo ensinados, contribuindo para a construção do conhecimento sobre tal ensino. Interessa-nos compreender como esses professores, apesar das dificuldades, trabalham com temas de FMC de forma regular, ou seja, terapêutica.

Os resultados indicam que as iniciativas dos docentes no ensino desses conteúdos não têm sido restritas a uma experiência isolada ao final do 3 ano do EM, em acordo com o que tem sido defendido pelos estudiosos da área.

Os materiais didáticos envolvendo FMC têm papel preponderante para que esses temas sejam incorporados aos currículos e planejamentos dos professores de Física. Os materiais carecem de uma transposição didática adequada ao nível de ensino, mas esse gargalo deve ser suplantado. Apesar dessas dificuldades, os professores utilizam materiais que eles próprios produzem ou adaptam, e isso sem sombra de dúvidas mostra uma criatividade didática por parte desses entrevistados, em busca de uma operacionalidade didática diferente dos tradicionais problemas e exercícios comumente utilizados na disciplina.

Ressalta-se, dentre os cinco entrevistados, que as práticas desenvolvidas por PA estão mais próximas de uma terapêutica didática, ou seja, estão mais fortemente presentes em suas aulas ano após ano. Em especial na prática efeito fotoelétrico ficou mais evidente a sua criatividade didática. Ele ressalta que quer mudar o seu encaminhamento metodológico, caracterizando uma busca de uma operacionalidade mais adequada, que neste caso não é aquela da forma tradicional utilizada no ensino da FC. Na prática da bomba nuclear ele demonstra uma maior satisfação, embora relate veementemente a não participação de alguns alunos nela, provavelmente por não reconhecerem a operacionalidade tradicional do ensino de Física na estratégia utilizada (o debate). Entretanto, conforme afirmam Brockington e Pietrocola (2005), não adianta oferecer algo novo em um recipiente velho: precisamos encontrar "novos recipientes", ou seja, uma nova operacionalidade didática é necessária com base em uma criatividade didática (elementos presentes na prática desse professor).

O processo de avaliação da aprendizagem, seus instrumentos e critérios, de forma análoga, constituem-se em outro elemento permeado por dúvidas e inseguranças, por vezes preso à tradicional cultura do ensino de Física. Uma prática pedagógica baseada em uma operacionalidade didática inovadora deve também trazer associados formas e instrumentos avaliativos condizentes com a operacionalidade proposta.

Finalmente, é importante ressaltar que esta investigação evidenciou que, apesar de todas as dificuldades, seja em relação às condições concretas ou à sua formação inicial, há professores ousando incorporar esses conteúdos na Física do EM.

\section{Referências}

BROCKINGTON, Guilherme. A realidade escondida: a dualidade onda-partícula para estudantes do ensino médio. Dissertação (Mestrado em ensino de ciências). IF -FE - USP, São Paulo, 2005.

BROCKINGTON, G. e PIETROCOLA, M. Serão as regras da Transposição Didática aplicáveis aos conceitos de Física Moderna? Investigações em Ensino de Ciências, v. 10, n.3, p. 387-404, 2005.

CHEVALLARD, Y. La Tranposicón Didáctica. Del Saber sábio al saber enseñado. Buenos Aires: Aique, 1997.

CHIZZOTTI, A. Pesquisa qualitativa em ciências humanas e sociais. 3ạ edição. Petropólis, RJ: Vozes, 2010.

D’AGOSTIN, Aline. Física Moderna e Contemporânea: com a palavra professores de Ensino Médio. Dissertação 
(Mestrado em Educação), Universidade Federal do Paraná, Curitiba, 2008.

FORQUIN, Jean-Claude. Escola e cultura: as bases sociais e epistemológicas do conhecimento escolar. Porto Alegre/RS: Artes Médicas, 1993.

GROCH, Tony Marcio. Práticas docentes no ensino de física moderna e contemporânea: entre tradições e inovações. Dissertação (Mestrado em Educação), Universidade Federal do Paraná, Curitiba, 2011.

KARAM, R.A.S. et al. Relatividades no ensino médio: o debate em sala de aula. Revista Brasileira de Ensino de Física, v. 29, n. 1, p. 105-114, 2007. cross $^{\text {ref }}$ http://dx.doi.org/10.1590/S1806-11172007000100017

KIKUCHI, L.A. et al. Ensino de Física Moderna e Contemporânea no Ensino Médio: uma análise do que se tem discutido a respeito. IX Encontro Nacional de Pesquisa em Educação em Ciências. IX ENPEC. Águas de Lindóia, SP, 2013.

LOCH, Juliana. Física Moderna e Contemporânea no planejamento dos professores de Física nas escolas públicas do Estado do Paraná. Dissertação (Mestrado em Educação), Universidade Federal do Paraná, Curitiba, 2010.

MONTEIRO, M. A.; NARDI, R. Tendências das pesquisas sobre o ensino da física moderna e contemporânea apresentadas no ENPEC. In: VI ENPEC - Encontro Nacional de Pesquisa em Educação em Ciências, Florianópolis, Santa Catarina, 2007.

OSTERMANN, F. e MOREIRA, M. A. Uma revisão bibliográfica sobre a área de pesquisa "física moderna e contemporânea no ensino médio". Investigações em Ensino de Ciências, v. 5, n. 1, mar. 2000.

. Sobre o ensino de Física Moderna e Contemporânea: uma revisão da produção acadêmica recente. Investigações em Ensino de Ciências, v.14, n.3, pp. 393-420, 2009.

PARANÁ/SECRETARIA DE ESTADO DA EDUCAÇÃO DO PARANÁ. Diretrizes Curriculares Estadual da Educação Básica. Curitiba: Secretaria de Estado da Educação do Paraná. 2008.

REZENDE JUNIOR, Mikael Frank. Fenômenos e a introdução de física moderna e contemporânea no ensino médio. Dissertação (Mestrado em Educação) UFSC, Florianopólis, 2001.

SAMAGAIA, R. e PEDUZZI, L. O. Q. Uma Experiência com o Projeto Manhattan no Ensino Fundamental. Ciência \& Educação, v. 10, n. 2, p. 259-276, 2004. cross $^{\text {ref }}$ http://dx.doi.org/10.1590/S1516-73132004000200008

TERRAZZAN, E. A. A inserção da física moderna e contemporânea no ensino de física na escola de $2^{\circ}$ grau. Caderno Catarinense de Ensino de Física, Florianópolis, v. 9, n. 3, p. 209-214, dez.1992.

Perspectivas para a inserção de física moderna na escola média. Tese (Doutorado em Educação), USP, São Paulo, 1994.

Recebido em março de 2014. Aprovado em maio de 2014. 